\title{
Impacts of Electric Vehicles on the Residential Distribution Network Based on the Time-of-use Power Price and Intelligent Charging
}

\author{
Zhihua Zanga, Yunpeng Liu, Ziqiang Xu, Lingming \\ Meng \\ North China Electric Power University, Baoding, China \\ ae-mail: zzhua19870610@sina.com
}

\author{
Yue Wang \\ State Grid Baoding Electric Power Supply Company, \\ Baoding, China
}

\begin{abstract}
The popularity of electric vehicle (EV) will greatly impact on the distribution network. An intelligent charging mode based on the current peak-valley time-of-use (TOU) power price is presented. Charging models of private EV under three charging modes in residential districts are established. Taking a $10 \mathrm{kV}$ feeder distribution network supplying power for residential districts in a city of South China as the case, then the impacts of EVs charging on the distribution network under three charging modes by 2020 and 2030 are analyzed. Controlled charging modes are beneficial to load curve smoothing, network loss reduction, reduce voltage deviation and load rate of the main equipments as well as meet EVs charging. And the intelligent charging presented is more effective. It provides a reference for renovation and planning of distribution network.
\end{abstract}

Keywords-electric vehicle (EV); distribution network; timeof-use (TOU) power price; intelligent charging

\section{INTRODUCTION}

The electric vehicle (EV) is an important way of promoting the development of clean energy. However, the large-scale EVs charging would produce great impacts on the distribution network structure and operation ${ }^{[12]}$. So it's of great significance to predict the impacts of EVs charging on the distribution network accurately for renovation and planning of the distribution network.

In view of pressures caused by EV charging, coordinated charging was presented in few references. [3] and [4] put forward time-of-use (TOU) power price to guide the charge and discharge of EV. But in fact most owners would start charging in the initial period of low price which is likely to produce a new peak load. Impacts of EV charging on distribution network load was analyzed in [5], without considering differences of charging power and duration demand of EVs. [6] and [7] presented intelligent charging, however, [6] ignored the owner's response degree to the intelligent charging, and charging power control of each EV in [7] was not easy to achieve. Acceptance ability of EV of IEEE-34 nodes distribution network was analyzed in [8], but it did not consider the TOU power price and smart charging.

As a matter of fact, EVs have different driving habits and charging demands. Moreover, charging behaviors are affected by the TOU power price. An intelligent charging mode based on the current peak-valley TOU power price is presented in this paper. Charging models of private EVs under three charging modes in residential districts are established. Taking a $10 \mathrm{kV}$ feeder distribution network supplying power for residential districts in a city of South China as the case, then the impacts of EVs on load curve, network loss, voltage deviation and the load rate of the main equipments under the three charging modes by 2020 and 2030 are analyzed.

\section{FACTORS INFLUENCING THE EV CHARGING}

Comparing with commercial vehicles such as buses, passenger vehicles are more random and flexible both on travel mileage and charging behavior, the adjustability of charging behavior is wide also, especially private EVs. Therefore, the paper takes private EVs as the research object. The reference EV types are BYD E6, Nissan Leaf and Tesla. Their parameters and proportions are shown in Table I .

TABLE I. PARAMETERS AND PROPORTIONS OF EV

\begin{tabular}{|c|c|c|c|}
\hline Reference EV type & E6 & Leaf & Tesla \\
\hline $\begin{array}{c}\text { Power consumption per hundred } \\
\text { kilometers (kWh/100km) }\end{array}$ & 21 & 15 & 24 \\
\hline Power of slow charging (kW) & 15 & 3 & 18 \\
\hline Proportion of private car (\%) & 30 & 60 & 10 \\
\hline
\end{tabular}

A. Travel Mileage

The probability density of private cars' daily travel mileage $^{[9]} X$ is

$$
f_{D}(x)=\frac{1}{x \sigma_{D} \sqrt{2 \pi}} \exp \left[-\frac{\left(\ln x-\mu_{D}\right)^{2}}{2 \sigma_{D}^{2}}\right]
$$

Where $\mu_{D}=3.2$ and $\sigma_{D}=0.88$.

\section{B. Last Trip to Home}

The last trip to home of private cars obeys normal distribution, the probability density function is ${ }^{[9]}$

$f_{S}(x)=\left\{\begin{array}{l}\frac{1}{x \sigma_{S} \sqrt{2 \pi}} \exp \left[-\frac{\left(x-\mu_{S}\right)^{2}}{2 \sigma_{S}^{2}}\right],\left(\mu_{S}-12\right)<x \leq 24 \\ \frac{1}{x \sigma_{S} \sqrt{2 \pi}} \exp \left[-\frac{\left(x+24-\mu_{S}\right)^{2}}{2 \sigma_{S}^{2}}\right], 0<x \leq\left(\mu_{S}-12\right)\end{array}\right.$

Where $\mu_{s}=17.6$ and $\sigma_{s}=3.4$. 
Owners of EVs finishing last trip to home may choose to charge or not, nevertheless, they are affected by power price and driving habits.

\section{Charging Duration}

Charging duration can be calculated by ${ }^{[9]}$

$$
T_{c}=S W_{100} / 100 \eta P_{c}
$$

Where $S, W_{100}$ and $P_{c}$ are daily travel mileage, power consumption of hundred kilometers and charging power (seen to be constant ${ }^{[5]}$ ) of $\mathrm{EV}$, respectively. $\eta$ is charging efficiency that values 0.9 .

\section{CHARgING MODES AND LOAD MODELS}

The TOU power price has been widely used. Therefore, the paper studies three charging modes: mode I is random charging based on the current peak-valley TOU power price, mode II is guided charging based on the TOU power price for $\mathrm{EV}$, and mode III is intelligent charging based on the current peak-valley TOU power price. The paper takes the current power price implemented in the city mentioned above as the case, residential power price: peak price time is 8:00-21:00 and valley price time is 21:00-8:00.

\section{A. Mode I}

Considering the current peak-valley TOU power price and user psychology, charging start time $t_{s}$ can be obtained according to (2).

Assume that $80 \%$ of EV owners choose to charge in residential districts everyday, and $10 \%$ among them do not response to the current peak-valley TOU power price and charge before $21: 00$. While $70 \%$ of owners charge after 21:00, however, they mostly want to finish charging as soon as possible, so charging start time $t_{s}$ may concentrate in the initial period of valley price with the use of timing device. It can be calculated according to (2) that $90 \%$ of private cars finish their last trip between 9:00 and 21:30, 7\% arrive home between $21: 30$ and 24:00, and only 3\% arrive between 0:00 and 9:00(seen to arrive before 24:00). Thus distribution of charging time is listed in Table II . $t_{s}$ obeys uniform distribution between $t_{a}$ and $t_{b}, t_{s}$ can be calculated by

$$
t_{s}=t_{a}+c \times\left(t_{b}-t_{a}\right)
$$

Where $C$ is a random number between 0 and 1 .

TABLE II. CHARgING TIME IN RESIDENTIAL Districts

\begin{tabular}{|c|c|c|}
\hline$t_{a}$ & $t_{b}$ & Proportion of EV (\%) \\
\hline $18: 00$ & $21: 00$ & 10 \\
\hline $21: 00$ & $21: 30$ & 63 \\
\hline $21: 30$ & $24: 00$ & 7 \\
\hline
\end{tabular}

Combining with Table I , Table II , (1), (3) and (4), charging power of one EV can be simulated by MATLAB, calculating 10,000 times using Monte-Carlo method. Charging power of one EV under mode I is shown in Fig. 1. Charge time of private EVs concentrates between 21:00-1:00, and charging power has obvious peak. It may overlap peak to the initial foundation peak load.

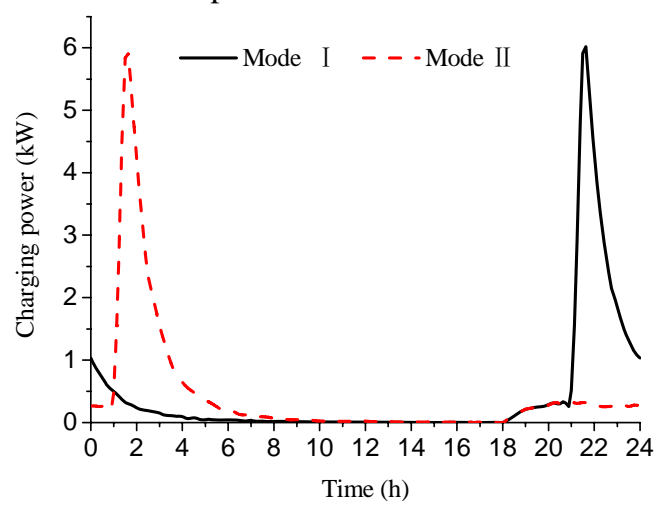

Figure 1. Charging powers of one EV under mode I and mode II

\section{B. Mode II}

To mitigate the probable problem of overlapping peak to peak load owning to mode I, this mode formulates TOU power price for EVs' charging specially to induce EV owners' charging behavior. Fast charging belongs to the rigid demand, the adjustable space is narrow while slow charging's adjustable space is wide. Moreover, charging load peak is slow charging which mainly appears in residential district at night. Therefore, the TOU power price for EV mainly aims at slow charging in residential district at night in the paper.

Similarly, considering power price and user psychology, charging time distribution of private EV can be calculated. The TOU power price setting ${ }^{[3]}$ and charging time distribution of private EV are shown in Table III.

TABLE III. TOU POWER PRICE SETting AND CHARging Time

\begin{tabular}{|c|c|c|c|}
\hline Time & Price & $\begin{array}{c}\text { Proportion of } \\
\boldsymbol{E V} / \boldsymbol{\%}\end{array}$ & $\begin{array}{c}\text { Charging start time } \\
\text { distribution }\end{array}$ \\
\hline 18:00-21:00 & price 1 & 10 & uniform distribution \\
\hline 21:00-1:00 & price 2 & 10 & uniform distribution \\
\hline 1:00-8:00 & price 3 & 60 & $\mathrm{U}(1,1.5)$ \\
\hline
\end{tabular}

Although the lowest price (price 3) period is sufficient for all the EVs to be fully charged, $t_{s}$ concentrates between 1:00-1:30 with taking driving habits and user psychology into account. Likewise, charging power of one $E V$ is calculated according to Table I, Table III, (1), (3) and (4), using Monte-Carlo method. In order to facilitate comparison, charging power under mode II is shown in Fig. 1 with mode I together.

It can be seen from figure 1 that comparing with mode I , mode II could transfer most of charging load of private EV from the first half of the night to wee hours, which is valley 
period of the original load without EV. Although it avoids peak of the original load, the charging power still has obvious peak.

\section{Mode III}

An intelligent charging mode is presented in this paper. EVs choosing slow charging just need to meet demand before the next travel. Mode III is based on the current peakvalley TOU power price, the strategy procedure is listed as follows.

Step 1) The intelligent charging system receives recent load curve of the distribution network without EV charging and charge demand data uploaded by communication module of each EV, such as EV type, battery capacity, state of charge (SOC), charging power and charging end time, etc.

Step 2) The intelligent charging system calculates charging duration of EVs and determines charging prioritization and serial number for each $\mathrm{EV}$.

Step 3) The optimizer embedded in intelligent charging system calculates the amount of EVs starting charging, corresponding serial number and charging start time of each EV during each time slot.

Step 4) If the results are is not optimal, it repeats step 3); else it executes step 5).

Step 5) The intelligent charging system closes the electric switches supplying power for charging devices in order according to the optimal charging start time of each EV.

Charging start time in step 3) is calculated by the mathematic model followed.

1) Objective function.

The model takes the minimum mean square error of distribution network load as objective function.

$$
\left\{\begin{array}{l}
\min T=\sum_{j=1}^{24}\left(P_{L j}+\sum_{i=1}^{n} P_{i j}-P_{a v r}\right)^{2} \\
P_{a v r}=\sum_{j=1}^{24}\left(P_{L j}+\sum_{i=1}^{n} P_{i j}\right) / 24
\end{array}\right.
$$

Where $P_{L j}$ is distribution network load without EV charging during slot $j ; P_{i j}$ is charging power of $\mathrm{EV} i$ during slot $j ; n$ is amount of EV scheduled; $P_{a v r}$ is daily average load.

2) Constraint condition.

Because of EV battery's charging characteristics, especially charging power constraint, the actual charging duration should meet the demand.

$$
\left\{\begin{array}{l}
t_{i c_{-} e}-t_{i c_{-} s} \geq T_{i c} \\
t_{i c_{-} e} \leq t_{i_{-} l}
\end{array}\right.
$$

Where $t_{i c_{-} e}, t_{i c_{-} s}$ and $T_{i c}$ are charging end time, charging start time and charging duration requested of EV $i$, respectively; $t_{i_{-} l}$ is end time requested.

SOC data are lack because the EV is not popular yet, therefore, travel mileages of EVs used in simulation are extracted randomly according to distribution of travel mileage stated in section II. Then charging duration of each EV is calculated by (3). Finally, amount of EV starting charging during each slot and charging start time of each EV are determined by Particle Swarm Optimization (PSO) procedure designed for the study.

\section{IMPACTS OF EV CHARGING}

The distribution network topology is shown in Fig. 2, the power source is $10 \mathrm{kV}$ bus bar of the $110 \mathrm{kV}$ transformer substation, and each node signifies a $10 / 0.4 \mathrm{kV}$ distribution substation. Total capacity of distribution transformers is 15.28MVA, number of transformers is 20, number of households is 1628 . According to prediction, the amount of private EV in the distribution network area are 125 and 488 by 2020 and 2030, respectively ${ }^{[10]}$. Residential districts are equipped with dispersive charging facilities used to slow charging mainly.

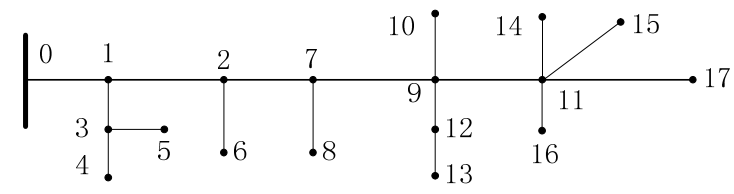

Figure 2. Network topology of the $10 \mathrm{kV}$ feeder

Assume that the power factor of EV charging is 0.9, charging loads in residential districts distribute in accordance with transformer capacity of each node. Charging loads of nodes can be calculated according to section III, then merge to initial foundation load without EV together to obtain total load of each node, finally power flow is calculated by OpenDSS software.

\section{A. Load and Loss Analysis}

Daily load curves of the distribution network under three charging modes and without EV by 2020 and 2030 are shown in Fig. 3 and Fig. 4. Peak load appears around 22:00 based on the current peak-valley TOU power price without EV charging in summer. 


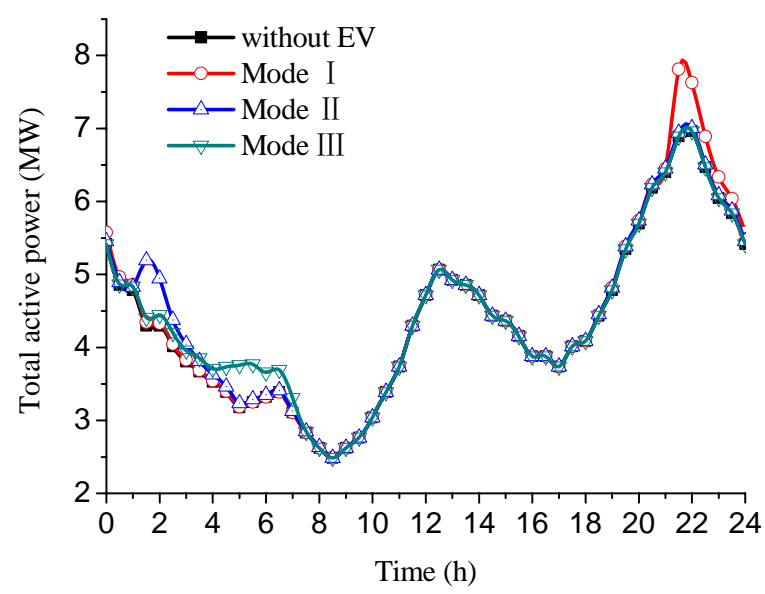

Figure 3. Load curves under different charging modes by 2020

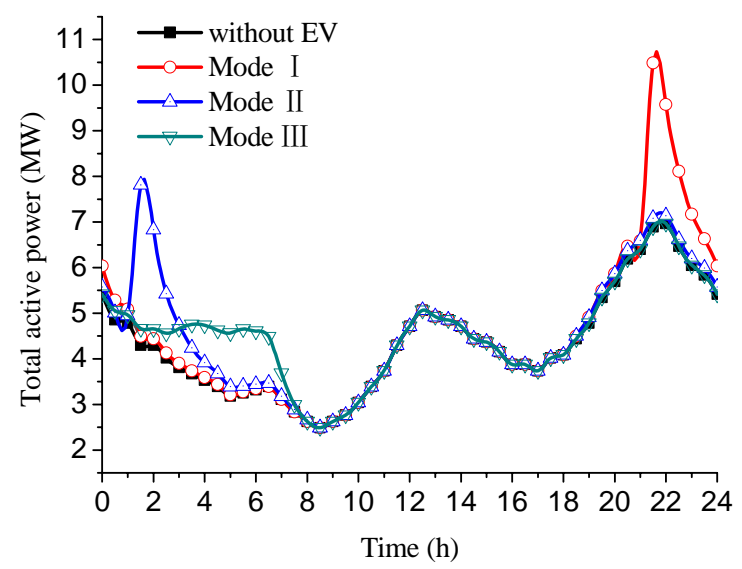

Figure 4. Load curves under different charging modes by 2030

Figure.3 and 4 indicate that under mode I, comprehensive load would increase drastically and unequally due to massive EV charging. Especially private EVs charging at night, and the owners are willing to start charging in the initial period of low price, which overlaps peak to peak load observably and impose great pressure to distribution network.

Under mode II, charging load could be transferred to wee hours which is valley load period of the initial foundation load, however, owners still choose to start charging in the initial period of low price with usage of timing devices, which forms new peak load. The more concentrated the time setting of timing devices is, the more obvious the peak is.

Mode III could reasonably transfer charging loads to offpeak period by adjusting charging start time of EVs. It transfers charging load from 20:00-24:00 to 0:00-7:30 evenly which is valley load period of the initial foundation load. The intelligent charging mode could avoid peak and full valley significant, rather than just move the peak under mode II . The more the EVs are, the more significant adjustment is.

Daily losses are shown in Table IV. Comparing with situation without EV, losses under mode I increase by
4.45\% and 19.39\% by 2020 and 2030, respectively. Losses under mode II increase by $3.07 \%$ and $13.78 \%$. Losses under mode III are just $1.13 \%$ and $5.44 \%$. Intelligent charging could reduce loss visibly. It is worth noting that these losses include line loss only, without transformer loss.

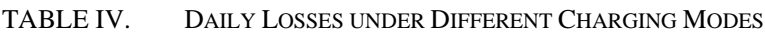

\begin{tabular}{|c|c|c|c|c|c|}
\hline & Year & $\begin{array}{c}\text { Without } \\
\text { EV }\end{array}$ & Mode I & Mode II & Mode III \\
\hline \multirow{2}{*}{$\begin{array}{c}\text { Daily loss } \\
\text { (kWh) }\end{array}$} & 2020 & 856 & 894.06 & 882.30 & 865.71 \\
\cline { 2 - 6 } & 2030 & 856 & 1022.07 & 973.94 & 902.58 \\
\hline
\end{tabular}

\section{B. Voltage Analysis}

The minimal node voltage curves by 2020 and 2030 are shown in Figure. 5 and 6. The minimal node voltage 0.989 under mode I by 2030 occurs in residential districts around $21: 30$. It is worth noting that if taking growth of foundation load into account, situation that voltage is under 0.93 may occur; The minimal node voltage 0.997 under mode II by 2030 occurs in residential districts around 1:30; Due to reasonable adjustment of charging start time, EV under mode III charge in order and would not lead to concentration phenomenon, voltage fluctuation and local maximal node voltage deviation are slight.

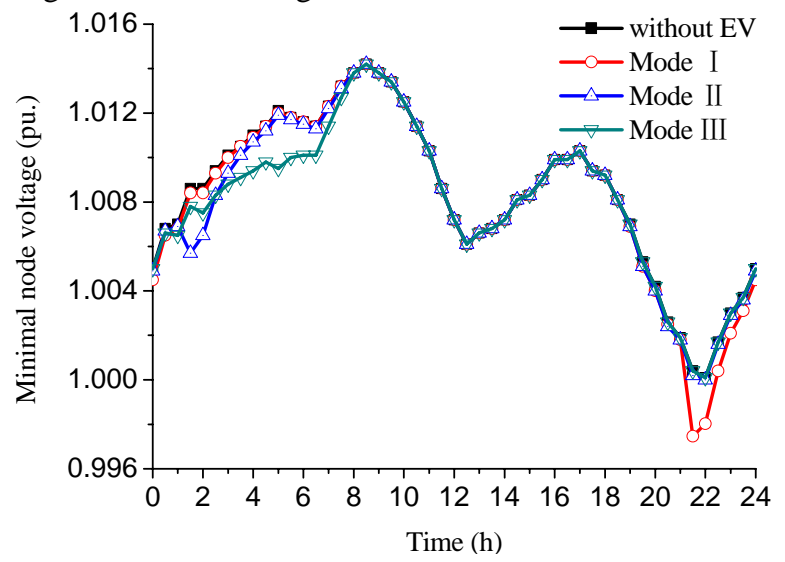

Figure 5. Minimal node voltage under different charging modes by 2020

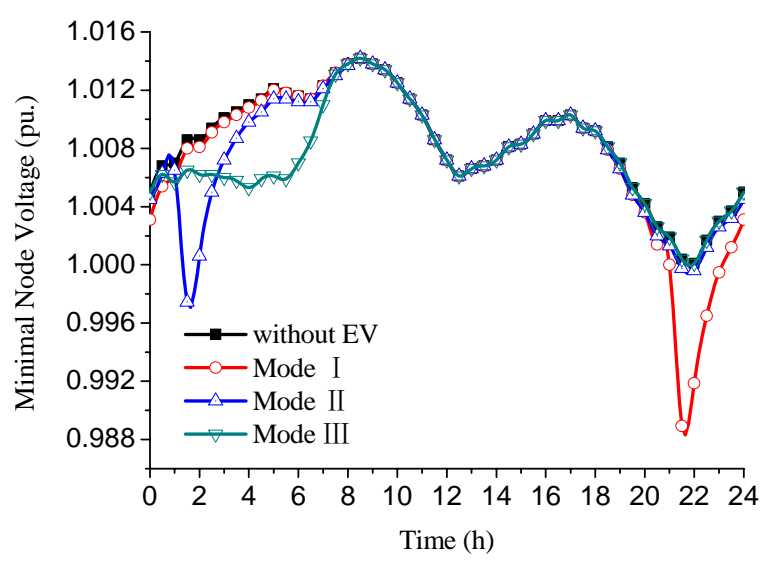

Figure 6. Minimal node voltage under different charging modes by 2030 


\section{Load Rate of Main Equipments}

\section{1) Line load rate}

Load rates of main lines by 2030 are shown in Table V . Averages of load rate under different modes increase slightly in comparison with that without EV. However, maximal load rates are high under mode $\mathrm{I}$, and most of them have exceeded 65\% which is the reference value of safe operation. One of the main reasons is charging loads' concentration at night. Load rates of mode II and III increase to different degrees in comparison to that without $\mathrm{EV}$, there is no situation that exceed $65 \%$, maximal load rates of mode II are high also. Load rates of mode III are almost the same to that without EV.

2) Transformer load rate

Load rates of transformers by 2020 and 2030 are shown in Table VI. Averages of daily load rate under different modes increase slightly in comparison with that without EV. However, average of maximal load rate is high and even few transformers appear overload situation under mode I . Average of maximal load rate is lower under mode II, few transformers are close to overload situation. The main reason of high load rate under mode I and II is that the charging loads distribute unevenly in time domain. Maximal load rate of mode III is the same to that without EV, there is no overload.

\section{TABLE V. LOAD RATES OF MAIN LINES}

\begin{tabular}{|c|c|c|c|c|c|}
\hline \multicolumn{6}{|c|}{ Load Rate of Main Lines (\%) } \\
\hline Line & & Without $E$ V & Mode I & Mode II & Mode III \\
\hline \multirow{3}{*}{ L1 } & Minimum & 18.77 & 18.83 & 18.99 & 18.77 \\
\cline { 2 - 6 } & Maximum & 52.66 & 79.47 & 59.13 & 52.66 \\
\cline { 2 - 6 } & Average & 32.98 & 35.64 & 34.88 & 33.16 \\
\hline \multirow{4}{*}{ L5 } & Minimum & 17.75 & 17.81 & 17.96 & 17.75 \\
\cline { 2 - 6 } & Maximum & 49.89 & 75.36 & 56.03 & 49.89 \\
\cline { 2 - 6 } & Average & 31.22 & 33.74 & 33.01 & 32.75 \\
\hline \multirow{4}{*}{ L7 } & Minimum & 19.84 & 19.90 & 20.07 & 19.84 \\
\cline { 2 - 6 } & Maximum & 55.82 & 84.41 & 62.71 & 55.82 \\
\cline { 2 - 6 } & Average & 34.90 & 37.73 & 36.91 & 35.41 \\
\hline \multirow{3}{*}{ L13 } & Minimum & 16.70 & 16.75 & 16.89 & 16.70 \\
\cline { 2 - 6 } & Maximum & 47.02 & 71.15 & 52.83 & 47.02 \\
\cline { 2 - 6 } & Average & 29.39 & 31.77 & 31.08 & 30.76 \\
\cline { 2 - 6 } & Minimum & 14.34 & 14.38 & 14.51 & 14.34 \\
\cline { 2 - 6 } & Maximum & 40.39 & 61.15 & 45.39 & 40.39 \\
\hline \multirow{2}{*}{ Average } & 25.24 & 27.28 & 26.69 & 25.89 \\
\hline
\end{tabular}

TABLE VI. LOAD RATE OF TRANSFORMERS

\begin{tabular}{|c|c|c|c|c|c|}
\hline \multicolumn{7}{|c|}{ Load Rate of Transformers (\%) } \\
\hline & Year & Without $\mathrm{EV}$ & Mode I & Mode II & Mode III \\
\hline \multirow{2}{*}{$\begin{array}{c}\text { Average of } \\
\text { maximal } \\
\text { load rates }\end{array}$} & 2020 & 50.61 & 56.80 & 50.90 & 50.61 \\
\cline { 2 - 6 } & 2030 & 50.61 & 76.28 & 56.79 & 50.61 \\
\hline $\begin{array}{c}\text { Average of } \\
\text { daily load } \\
\text { rates }\end{array}$ & 2020 & 31.49 & 32.00 & 32.00 & 32.01 \\
\cline { 2 - 6 } & 2030 & 31.49 & 33.45 & 33.38 & 33.30 \\
\hline $\begin{array}{c}\text { Proportion } \\
\text { of } \\
\text { overload }\end{array}$ & 2020 & 0 & 0 & 0 & 0 \\
\cline { 2 - 6 } & 2030 & 0 & 15 & 0 & 0 \\
\hline
\end{tabular}

Load rate of main equipments with initial foundation load is low under normal circumstances. So the results show that EV charging impacts greatly on load rate of lines and transformers. There are overload situations under mode I . If taking growth of foundation load by year into account, the situation would be worse. Therefore, it must consider upgrading and reconstruction of the main equipments, such as capacity-increase, etc.

\section{CONCLUSIONS}

With the popularity of EV, random charging based on the current peak-valley TOU power price would impact greatly on the urban distribution network. The TOU power price for $\mathrm{EV}$ can yet be regarded as an effective means, however, it could reduce the comprehensive influence on the distribution network to a certain extent. The intelligent charging based on the current peak-valley TOU power price proposed in the paper could provide a smooth load curve, low network loss, low voltage deviation and low load rate of the main equipments as well as satisfied serve of EVs charging. The intelligent charging could improve the security, reliability and economical efficiency of distribution network operation.

Simulation shows that main equipments under random charging based on the current peak-valley TOU power price and would overload to different extent by 2030. Main equipments under guided charging based on the TOU power price for EV is close to the limit of safe operation. In addition, if taking growth of foundation load by year into account, the situations of off-limit and overload would be worse and the voltage of $10 \mathrm{kV}$ side would not meet the requirements probably. The paper could provide a reference for renovation and planning of the distribution network with EVs charging.

\section{ACKNOWLEDGMENT}

The authors thank North China Electric Power University for its help in the work.

\section{REFERENCES}

[1] GAO Ciwei, ZHANG Liang, "A Survey of Influence of Electrics Vehicle Charging on Power Grid, ”Power System Technology, vol. 35, no. 2, pp. 127-131, 2011.

[2] Mohamed S, EINozahy and Magdy M. A. Salama, “AComprehensive Study of the Impacts of PHEVs on Residential Distribution Networks," IEEE Transactions on Sustainable Energy, vol. 5, no. 1, pp. 332-342, 2014.

[3] GE Shaoyun, HUANG Liu and LIU Hong, "Optimization of peakvalley TOU power price time-period in ordered charging mode of electric vehicle," Power System Protection and Control, vol. 40, no. 10, pp. 2316-2321, 2012.

[4] YU Haoming, HUANG Chun, XHANG Lei and ZHAO Wei, "Coordinated Charge and Discharge Control Strategy Based on Timeof-use Price from Electric Vehicle Customer Side,” ELectric Power, vol. 47, no. 12, pp. 95-98, 2014.

[5] GONG Xin, LIN Tao and SU Binghua, "Impact of Plug-in Hybrid Electric Vehicle Charging on Power Distribution Network," Power System Technology, vol. 36, no. 11, pp. 30-35, 2012.

[6] LI Qiushuo, XIAO Xiangning, GUO Jing and LIU Lin, "Research on Scheme for Ordered Charging Electric Vehicles," Power System Technology, vol. 36, no. 12, pp. 32-38, 2012. 
[7] LI Huiling, BAI Xiaomin, "Impacts of Electric Vehicles Charging on Distribution Grid,” Autimation of Electric Power Systems, vol 35, no. 17, pp. 38-43, 2011.

[8] HUANG Bibin, KONG Weizheng, LI Qionghui, "Capability Study of Typical Power Grid in Accommodating Electric Vehicles in China," Electric Power, vol. 46, no. 10, pp. 91-95, 2013.
[9] TIAN Liting, SHI Shuanglong and JIA Zhuo, "A statistical model for charging power demand of electric vehicles," Power System Technology, vol. 11, no. 34, pp. 126-130, 2010.

[10] LUO Zhuowei, HU Zechun, SONG Yonghua, YANG Xia and ZHAN Kaiqiao, "Study on Plug-in Electric Vehicles Charging Load Caculating”, Autimation of Electric Power Systems, vol. 35, no. 14, pp. 36-42, 2011. 